\title{
The impact of children on divorce risk
}

\author{
Qi X ${ }^{1^{*}}$, Jianning $Y u^{2}$ and Zeqi Qiu ${ }^{3}$
}

\footnotetext{
* Correspondence: xuqi@nju.edu.cn ${ }^{1}$ School of Social and Behavioral Sciences, Nanjing University, 163 Xianlin Avenue, Qixia District, 210023 Nanjing, Jiangsu Province, China

Full list of author information is available at the end of the article
}

\begin{abstract}
Based on the data of the first wave of the Chinese Family Panel Study in 2010, this paper studies the relationship of divorce risk and four variables related to children in China: premarital births and number, age, and gender of children. We find that all four variables have significant effects on divorce risk. Specifically, (1) couples who have premarital children are more likely to divorce; (2) the higher the number of children, the more stable the marriage, but the marginal effect declines with the increase of the number of children; (3) younger children reduce the risk of divorce more than older ones; and (4) couples who have sons are less likely to divorce. All these findings are consistent with studies conducted in other countries and suggest that children play an important role in stabilizing marriage and resolving conflicts in marriage. We also find that the positive effect of children on marital stability and the effect of children's gender are stronger in rural areas, which is due to the differences in modernization and cultural values between rural and urban areas. These findings imply that changes in marriage values and the decline of the fertility rate are two important causes of the recent increase of the divorce rate in China.
\end{abstract}

Keywords: Divorce risk; Premarital birth; Number of children; Children's age; Children's gender; Rural-urban differences

\section{Background}

Research question

As a "media of binding couples biologically and psychologically" (Fei 1999), the presence of children is generally considered to be an important guarantee of stability in a marital relationship (Waite and Lillard 1991; Heaton 1990; Thornton 1977). Children are not only the most important investment in a marriage (Becker 1973; Becker et al. 1977) but can also enhance the emotion and interdependence between husband and wife (Durkheim 2000; Waite and Lillard 1991). Therefore, couples with children have a lower divorce risk.

However, empirical studies have found that the relationship between children and marital stability is very complex. First, having children is not always a beneficial factor for the stability of a marriage (Waite and Lillard 1991). Second, in the dynamic process of children growing up, children's effect on the stability of marriage changes (Heaton 1990). Finally, the impact of children differs by gender. Studies have found that having sons is more protective of the stability of marriage (Morgan et al. 1988).

Compared with rich theoretical and empirical research, there has not yet been a systematic study that investigates the relationship between children and divorce risk in the unique context of China. Based on the first wave of the Chinese Family Panel Study (CFPS) in 2010, this study explores this issue for the first time. In China, the 
subsequent impact of the one-child policy on family life is gradually emerging. Therefore, exploring the factors influencing family stability from the perspective of children is not only of theoretical significance but also of important practical significance.

First, because of unique cultural traditions, the divorce rate in China was very low during its long history (Ye and Lin 1998; Zeng 1995). However, since the 1980s, China's crude divorce rate has maintained an increasing trend. As is shown in Figure 1, in 1979 , the number of divorces was 319,000, and the crude divorce rate was only 0.3 per thousand; in 2009, however, these two statistics rose to 2.468 million and 1.85 per thousand, respectively. The average annual growth rate was $7.1 \%$ and $6.3 \%$. Compared with the gradual rise prior to 2000, both the number of divorces and the crude divorce rate accelerated after 2000 .

Second, since the implementation of the family planning policy in the 1970s, China's birth rate has decreased steadily. During the past 30 years, the total fertility rate (TFR) quickly dropped from a high level of close to six in 1970 to below the replacement level (2.1) at the beginning of the $1990 \mathrm{~s}^{\mathrm{a}}$. As is shown in Figure 2, though the TFR values based on different data sources are not uniform, the declining trend is obvious.

Thus, there is a rapid decline of the total fertility rate on the one hand and a substantial increase in the crude divorce rate on the other. Although this study does not focus exclusively on the association between the two, the simultaneous change in the divorce and fertility rates at the macro-social level makes the study of the stability of marriage from the perspective of children more meaningful.

Moreover, the uniqueness of Chinese society lies in the dual-division system between urban and rural areas. Urban and rural areas not only differ significantly at the level of modernization and cultural values but also display a huge difference in divorce rates (Wu 1999; Zeng 1995) and fertility rates (Guo 2004). This study explores whether these disparities affect the association between children and divorce risk differently in urban and rural areas.

\section{Hypotheses}

The theoretical framework of the association between children and marital stability is shown in Figure 3 (Thornton 1977). Certain theories posit that the presence of children has a direct effect on marital stability (Figure 3,a). From the perspective of economists, children are a marital-specific capital, which, on the one hand, can

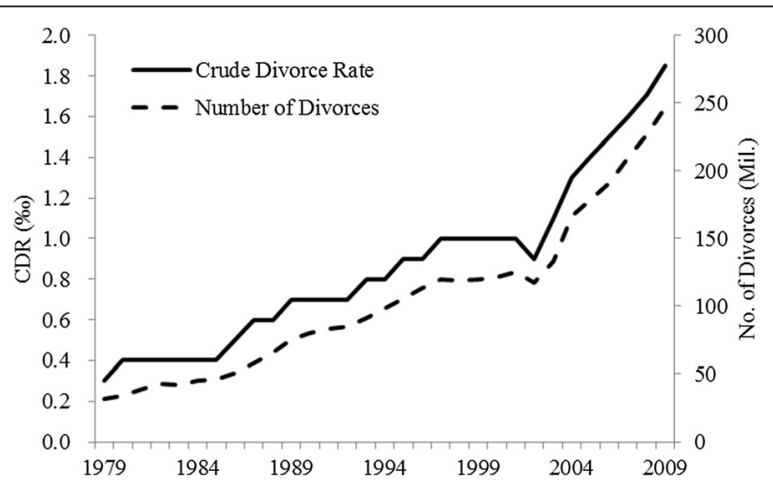

Figure 1 Growth curve of number of divorces and crude divorce rate since 1978. Data source: Institute of Population and Labor Economics (2010). 


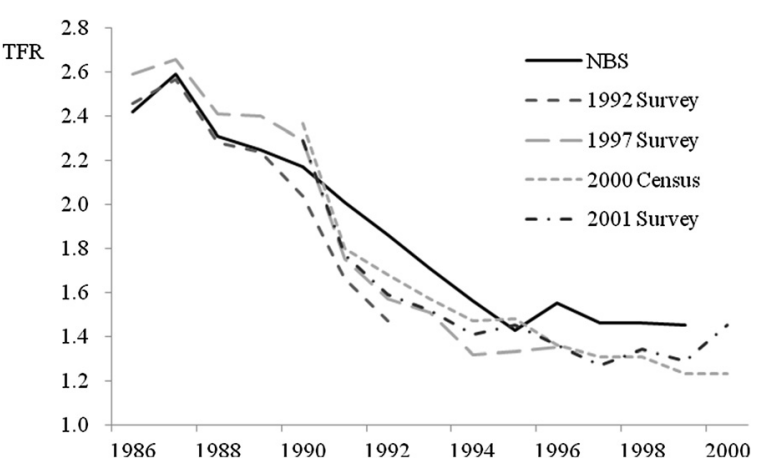

Figure 2 Total fertility rate based on different data sources.

enhance the attractiveness of the current marriage and, on the other hand, can increase the cost of divorce. Thus, couples with children are less likely to divorce (Becker 1973; Becker et al. 1977). Unlike other forms of marital capital, the couple naturally jointly possesses their children, and the more children a couple have, the more common property they possess (Becker 1973). Divorced women with children find it more difficult to remarry relative to those who do not have children, thus having children increases the cost of divorce for women (Teachman and Heckert 1985).

In contrast to economic theories, sociological theories focus more on children's effects on the division of labor within the family. The birth of a child creates "a common work and career" for the couple (Fei 1999). In the process of raising children together, interdependence is established between the couple through the division of labor. This "organic solidarity" is beneficial for maintaining a stable marital relationship (Durkheim 2000; Waite and Lillard 1991; Morgan et al. 1988).

Raising children requires enormous time, money, and emotion from both sides of a couple (Heaton 1990). Once divorced, the party (usually the father) that loses child custody is usually alienated from their children, destroys their relationship with their children, and then suffers severe mental anguish (Furstenberg et al. 1983). For the party (usually the mother) that obtains custody, the divorce can bring serious difficulties in life because the entire burden falls on one person's shoulders (Waite and Lillard 1991). Therefore, in order to avoid its adverse effects, some couples may abandon the intention to divorce (Thornton 1977). Moreover, after having children, pressure from social norms and cultural traditions are stronger in discouraging divorce (Waite and Lillard 1991). Studies have found that most couples believe that divorce is harmful for children. For the sake of their children's healthy growth, some emotionally damaged

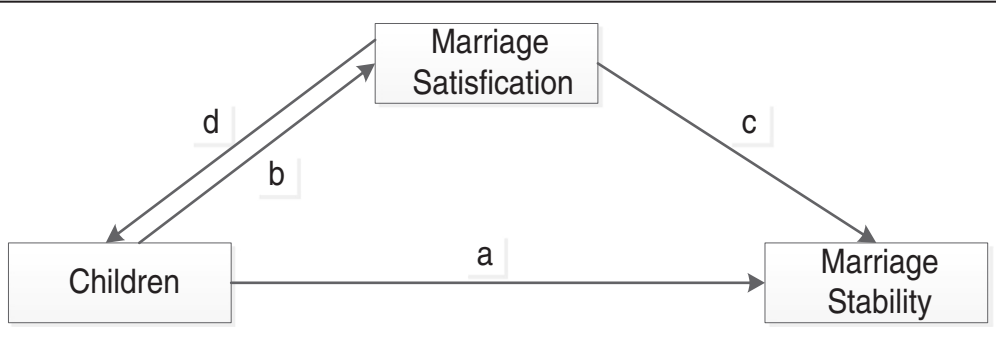

Figure 3 Theoretical framework of the association between children and marriage stability. 
couples may choose to continue the marriage (Thornton 1977; McLanahan and Bumpass 1988).

In addition to the direct impacts mentioned above, children may also affect the stability of marriage indirectly (Figure 3,c) through marital satisfaction (Figure 3,b). Some studies suggest that having children itself is a source of happiness (Heaton 1990). Watching children growing day by day, the couple gains a sense of accomplishment and happiness (Hoffman and Manis 1978). As a third party, children become a couple's "media for bonding psychologically" (Fei 1999), and thus contribute to adjusting the couple's relationship and resolving disagreements (Thornton 1977).

Other studies suggest that children have a negative impact on marital satisfaction (Belsky et al. 1983). Parenting is not an easy thing. After the child is born, the couple must undergo a significant adjustment to adapt to their new role as parents; the higher the number of children, the more difficult the adaptation. Sometimes, the children themselves can become the root causes of conflicts between the couple (Rollins and Galligan 1978; Worthington and Buston 1986). For example, after having children, a fundamental change occurs in a couple's assignment of housework, work, and leisure time. The result is less and less time for emotional communication between the husband and wife. Empirical studies have found that couples with children have lower marital satisfaction (Belsky et al. 1983; Hoffman and Manis 1978). This low level of satisfaction has been interpreted differently. Some people believe that the presence of children may negatively affect marital satisfaction because children are like a kind of glue that can stick the dissatisfactions together (Glenn and Mclanahan 1982).

Finally, marital satisfaction may also affect the decision to bear children (Figure 3,d). People in marriages with conflicts have a lower desire. Unhappy marriages may lead to lower frequency of sexual intercourse and may result in the couple using more effective means of contraception and even abortion to avoid unwanted pregnancies (Udry 1971). Although some studies suggest that divorce risk and the number of children have a negative relationship, a different interpretation thus exists. When couples are facing potential divorce, they are less likely to have children (Thornton 1977).

Theoretically, children can have both a positive impact on the stability of marriage (positive direct effect $a$ and positive indirect effect of $b \times c$ ) and a negative impact (negative indirect effect of $b \times c$ ). The relationship between children and marital stability may also be spurious, caused by common factors of marital satisfaction (Figure 3; marital satisfaction affects both the presence of children $d$ and the stability of the marriage). Such theoretical complexity results in the complexity of empirical findings.

Under different conditions, children may have different effects on the stability of marriage. First, the time of birth is important. Some studies found that premarital birth is not favorable to the stability of a marriage, while the birth of children after a marriage has a positive effect (Waite and Lillard 1991). Premarital birth can force the young couple to take on the responsibility of parenthood before they have accumulated the necessary material wealth and emotional foundation. Before they can enjoy their marriage, couples with premarital birth must face a heavy family burden both financially and emotionally (Waite and Lillard 1991). Premarital birth makes a difficult life more likely, and overwhelming situations can increase the likelihood of divorce (Freedman and Thornton 1979). Moreover, in China, premarital birth contradicts the traditional cultural values, so these children are more vulnerable to criticism and questioning from 
others. At the same time, premarital birth also reflects the fact that the couple may have an open attitude toward marriage, and couples with open attitudes are usually more vulnerable to divorce (Xie 2006). Based on this, the first hypothesis examines whether the negative relationship between premarital birth and divorce risk also applies in China.

\section{Hypothesis 1: Couples with premarital birth have a higher divorce risk.}

Second, the number of children is important. Most studies suggest that the number of children has a linear relation with divorce risk in that the greater the number of children, the lower the risk of divorce (White 1990; Waite and Lillard 1991; Hoem and Hoem 1992; Goode 1993; Tzeng and Mare 1995; Weiss and Willis 1997; Jalovaara 2001; Coppola and Di Cesare 2008). However, some researchers have found that the number of children and divorce risk has a U-shaped nonlinear relationship and that either too many or too few children are not favorable to the stability of a marriage (Thornton 1977). Intuitively, an increase in the number of children increases a couple's marriage capital and improves and promotes the couple's feelings and interdependence, but these gains may have a diminishing marginal effect. As the number of children increases, the burden of raising children becomes increasingly heavy and the negative impact from children also increases. Therefore, the nonlinear relationship may be more realistic.

The second hypothesis thus tests whether a nonlinear relationship exists between the number of children and divorce risk.

Hypothesis 2: The higher the number of children, the lower the risk of divorce; however, once the number increases more than the marginal quantity, it increases the risk of divorce.

Third, children's age has an impact on the risk of divorce (Heaton 1990). Studies have found that younger children can lower the divorce risk. As age increases, children's role in protecting a marriage becomes weaker (Heaton 1990; Bracher et al. 1993; Andersson 1997). Some studies have even found that children over the age of 13 may adversely affect the stability of a marriage (Waite and Lillard 1991). Possible interpretations are that taking care of young children requires a great deal of time and effort (Cherlin 1977). When children are younger, the husband and wife can maximize their benefit through the division of labor. Once divorced, the entire burden falls on the shoulders of one person, and this is not what the couple wants (Waite and Lillard 1991). As children grow up, the school bears a part of the children's custody; on the other hand, when children become more independent emotionally and financially, the couple will receive less in return through the division of labor (Waite and Lillard 1991). Parents may believe that divorce poses greater harm to young children, so in order to allow children to grow up in a healthy way, parents are more reluctant to get divorced when children are young (Heaton 1990). Based on this, the third hypothesis of this study is to verify whether the protective effect of children on marriage is stronger when children are younger.

Hypothesis 3: Younger children have a stronger protective effect on marriage. 
Finally, studies have found that boys are more favorable to the stability of marriage (Morgan et al. 1988). Fathers play a more important role in raising sons, and thus are more involved in family issues. In this case, the wife feels more satisfied with the husband, and thus, the stability of the marriage is higher (Morgan et al. 1988). Similar findings also appear in the study of divorce tendency. Katzev et al. (1994) find that compared to mothers with sons, mothers who have only daughters think that their marriages are more likely to end in divorce. However, some researchers have found that children's gender does not significantly affect divorce risk (Andersson and Woldemicael 2001; Diekmann and Schmidheiny 2004).

In order to test the effect of children's gender, we propose a fourth hypothesis:

\section{Hypothesis 4: Couples with sons have a lower divorce risk.}

Compared to Western society, Chinese society has unique characteristics. To some extent, divorce was prohibited since ancient times in China because of its potential harm to marriage stability and violation of the dominant Confucian laws. In traditional Chinese culture, the intent of marriage was not the love and happiness of the husband and wife but to produce children, especially sons, to keep the family name alive (Zeng 1995). Therefore, childbearing and childrearing are inherent purposes of Chinese marriage. This is essentially different from Western society, where marriage is a private, matter and getting a divorce is perceived as an act of freedom (Zeng 1995). If children stabilize marriages and parents need to make sacrifices in order to raise children, this kind of stabilizing effect and sacrifice should be more evident in Chinese society.

However, with the opening of China, Western values are increasingly exerting their impact on Chinese people's attitudes and concepts, and the traditional Chinese concept of marriage may be changing (Ye and Lin 1998). In urban areas, this change may be more significant, while in relatively isolated rural areas, the traditional concept of marriage may still play a role. Therefore, the protective effect of children on marriage should be stronger in rural areas. In view of this, we propose a fifth hypothesis:

\section{Hypothesis 5: The protective effect of children on marriage is stronger in rural areas} than in urban areas.

Moreover, the uniqueness of Chinese society is also reflected in the strong son preference. For cultural purposes such as carrying on the family line and practical purposes such as raising children for future old-age care, Chinese couples prefer boys. This gender preference may result in couples raising children in different ways. Given the country's strict limitation on the number of births, if the wife does not give birth to a boy, it may cause fundamental conflicts for couples. Once again, this gender preference is stronger in rural areas.

This study thus argues that the impact of children's gender should be more evident in rural areas in China. Our sixth hypothesis states

Hypothesis 6: The impact of children's gender on divorce risk is stronger in rural areas than in urban areas. 


\section{Methods}

The data used in this study was drawn from the first wave of the CFPS in 2010. CFPS is a large-scale comprehensive social survey conducted by the Institute of Social Science Survey at Peking University. This survey employs an implicit stratified multistage PPS sampling design and covers 25 provinces in mainland China (excluding Inner Mongolia, Xinjiang, Tibet, Hainan, Ningxia, and Qinghai), representing about 95\% of the Chinese population.

In the first wave of CFPS, each family was asked to complete a family-member questionnaire regarding the relationship of family members living together, as well as basic demographic and socioeconomic information regarding themselves, their parents, their spouses, and their children. Each of the surveyed households then answered a household questionnaire to gather further information on household income, expenditures, housing, living conditions, and other family issues. Finally, each family member in the household answered a personal questionnaire. There were two versions of this questionnaire, the child's version and the adult's version, based on the respondent's age. The personal questionnaire included questions on education, work, marriage, health, time use, and so on.

In the first wave of data collection in 2010, CFPS received a total of 14,960 valid familymember questionnaires, 14,798 household questionnaires, 33,600 adult questionnaires, and 8,990 child questionnaires. This study is mainly based on the adult sample, but unmarried respondents were removed from the analysis. The unit of analysis is the pair in the "first marriage." If both spouses in their first marriage answered the adult questionnaire, they were counted as one couple. After deleting unreasonable values ${ }^{\mathrm{b}}$ and removing missing values, 16,466 pairs of first marriages entered into the analysis.

CFPS asked about each couple's marital history, including the date of their first marriage, respondent's birth date and that of their first spouse, whether their first marriage ended in divorce and the date of divorce, and whether their first spouse died and the date of death. In addition, CFPS also asked about the reproductive history of each couple, including the birth date of each child and child's gender. Based on this information, we can analyze in detail how timing of births and number, age, and gender of children affect the divorce rate during the family life cycle.

Except for premarital birth, all the independent variables associated with children, namely number of children, children's age structure, and gender structure, change throughout the duration of the marriage. These three variables are time-varying variables. Time-varying variables can capture the changes that occur over time; due to the introduction of time, the value of independent variables always precedes that of the dependent variables, and causation is clearer. Even so, the analysis is still not completely unaffected by the possibility of reverse causation. Couples may feel divorce is a future risk and intentionally suppress current fertility (Figure 3,d).

In terms of operationalization, the existence of premarital birth is a dichotomous variable. If the birth of the respondents' first child occurred earlier than the date of marriage, the value is assigned 1 , otherwise 0 .

The number of children refers to the absolute number of children that couples have at a specific time point, and is thus a time-varying variable.

Four variables report children's age structure, namely the number of children aged 0 , the number aged 1 to 5 years, the number aged 6 to 12 years, and the number of 
children aged 13 and over. The total of the four variables is the total number of children couples have at a particular point of time. This categorization is based on the findings of Waite and Lillard (1991), who find that couples experience a "honeymoon" period after each new birth and that the marriage is most stable during these times. Preschoolers (children under 6 years old) are strongly dependent on their parents, so couples' divorce risk is relatively low; however, children over the age of 13 adversely affect the stability of marriage. To test the applicability of these findings in China, this study divided children into the four groups shown above.

The variable reflecting the gender structure of child is a dichotomous variable. If the couple gave birth to boy(s) before a particular point of time, the value is 1 , otherwise 0 .

In addition to these key independent variables, duration of marriage, date of marriage, provinces, urban or rural areas, wife's age at first marriage, and education were also controlled in the analysis. Since these variables are relevant to both independent and dependent variables, they must be controlled in the model.

Studies have found that divorce risk shows an inverted U-shaped curve in the duration of the marriage (Vignoli and Ferro 2009; Lyngstad 2004); number of children, gender, and age structure also changes with the duration of the marriage. Therefore, duration of marriage has to be controlled. Applying the Cox proportional hazards model to this study intrinsically controls for the duration of marriage and so avoids this problem.

Second, existing research also found that influenced by national policy, China's divorce rate differed significantly in different historical periods (Zeng 1995). In the early years, China experienced a peak in the divorce rate; later, affected by the Cultural Revolution in the late 1960s and throughout the 1970s, China's divorce rate dropped to a very low level (Ye and Lin 1998). During the implementation of the reform and opening-up policy and the promulgation of the new Marriage Law in the 1980s, China's divorce rate began to rise continuously (see Figure 1).

Due to different fertility policies, China's birth rate also differs significantly in different historical periods. In order to avoid interference, this study divides the entire time span into five periods: the first period is prior to 1966 when the Cultural Revolution began; the second period spans from the beginning of the Cultural Revolution in 1966 to the promulgation of the new Marriage Law in 1980; the third period is the early years of reform and opening up from 1981 to 1991; the fourth period is from 1992 to 1999 when the economic reform in China accelerated; and the fifth period begins in 2000 when China entered the new century. Figure 1 shows that this period has witnessed a significantly rapid rise in the divorce rate. Historical period is also a timevarying variable because over the duration of a marriage, the couple may experience a number of historical periods.

Once again, China's divorce rates also showed significant regional differences and urban-rural differences (Zeng 1995). Due to differences in the level of social development, cultural traditions, and fertility policies among different provinces and between urban and rural areas, fertility rates also have significant regional differences. In order to eliminate confounders, provinces and urban/rural are also controlled in the model. Specifically, CFPS investigated a total of 25 provinces; in the analysis, they are treated as fixed effects. Rural-urban division is based on whether respondents have a village committee or residential committee. This is not only an important control variable, but in its interaction with children, it is also an important factor studied by this work. 
Because of migration and mobility, place of residence may change over time; thus, the provinces and urban/rural areas are also time-varying variables. However, the data did not collect the migration history of respondents, so we can only control for the provinces and the urban/rural areas in which respondents currently reside. In addition to residential areas, household registration status can also be used to determine urban/ rural areas. This study used the residential area to distinguish rural from urban for two main reasons. First, migrants from rural to urban areas have a certain particularity, and because of their urban experiences, their concept of marriage and childbearing may change. Thus, merging them with those left behind in rural areas may not be appropriate. Second, defining urban/rural according to household registration can bring ambiguities in the operationalization because the husband and wife may have different household registration status. For couples living in two separate places, especially people who have been divorced, we only have the information of the individual answering the questionnaire, which makes it difficult to operationalize. In order to test sensitivity, we also repeated the analysis by using household registration status to distinguish rural from urban and found that the results are consistent.

Finally, some studies have found that couples' level of education and age at first marriage also affect divorce risk. Years of education indicate the openness of the concept of marriage; thus, the higher the level of education the more likely they are to divorce. Studies on age at first marriage show that marrying too young is not beneficial to the stability of a marriage (Waite and Lillard 1991; Heaton 1990). Empirically, the husband's age at first marriage and years of education have a strong correlation with the wife's, but the impact of years of education and age of the wife on birth is more direct, and therefore, we control for the wife's age at first marriage and years of education in this study.

Table 1 describes the basic descriptive statistics of all 16,466 couples at the beginning of the marriage. The sample consists of $12.5 \%$ of couples married prior to $1966,23.8 \%$ married during 1966 to 1980, 29.0\% married during 1981 to 1991, 16.7\% married during 1992 to 1999 , and $18.1 \%$ married after $2000^{\mathrm{c}}$. Two-thirds of the sampled couples

Table 1 Descriptive statistics on when couples married

\begin{tabular}{lccc}
\hline Variable & Category/index & Percentage/value & Sample size \\
\hline Historical period (year) & Prior to 1966 & 12.5 & 2,057 \\
& 1966 to 1980 & 23.7 & 3,911 \\
& 1981 to 1991 & 29.0 & 4,770 \\
& 1992 to 1999 & 16.7 & 2,755 \\
& 2000 to 2010 & 18.1 & 2,973 \\
Urban/rural & Rural & 67.0 & 11,041 \\
& Urban & 33.0 & 5,425 \\
Wife's age at first marriage & Mean & 22.0 & 16,466 \\
& S.D. & 3.7 & 16,466 \\
Wife's years of education completed & Mean & 5.4 & \\
Premarital birth & S.D. & 4.9 & 15,759 \\
& No & 95.7 & 707 \\
\hline
\end{tabular}

Note: wife's age at first marriage and education completed is measured in "year"; all other figures are percentage. 
lived in rural areas, and one-third lived in urban areas. The average age of wives at first marriage was 22.0 years old, and the average duration of education was 5.4 years. The percentage of sampled couples who had children before getting married was 4.3.

Table 2 describes the change in number of children, age, and gender structure in the duration of the marriage. As seen, over the duration of marriage, the number of children increases, the number of older children increases, and the number of young children decreases. With the increase in the number of children, the proportion of having boys also increases.

Note that in Table 2, the size of the sample dwindles with the duration of marriage for two reasons. First, some divorced or widowed couples ended their first marriage before 2010. These couples do not appear in subsequent years after divorce or losing a spouse. Second, some married couples only had a very short marriage history when they were surveyed. For example, couples that married in 2006 cannot be part of the sample of marriages of 10 or 20 years when they were surveyed in 2010.

This problem of data censoring also appears in Table 3. Table 3 describes the marital status of all 16,466 couples in their first marriage when surveyed in 2010. As can be seen, most couples are still in their marriages, but this does not indicate that they will not divorce in the future. For this data-censoring problem, survival analysis is currently the best statistical model.

The statistical model used in this study is the Cox proportional hazards model. This model has advantages over other survival models (Allison 1995). First, it is a semiparametric model, which means it does not require presetting the function form of the divorce hazard. Second, though its assumptions are weaker than parametric models, model estimates still have good statistical properties, and the efficiency of statistical tests does not suffer greatly. Third, with respect to parameter models, the Cox proportional hazards model can easily deal with time-varying independent variables, such as the number, age, and gender of children. Therefore, this model is ideal for our research purposes.

The formula of the Cox proportional hazards model is as follows:

$$
\log h_{i}(t)=a(t)+\beta x_{i}+\gamma x_{i}(t)
$$

where $h_{j}(t)$ refers to the divorce hazard of couple $i$ after $t$ years of marriage, and $\alpha(t)$ characterizes the variation of divorce risk in the duration of marriage, that is, the

Table 2 Changes in number of children, children's age, and gender in the duration of marriage

\begin{tabular}{lcccc}
\hline Variable & $\begin{array}{c}\text { 2 years after } \\
\text { marriage }\end{array}$ & $\begin{array}{c}\mathbf{5} \text { years after } \\
\text { marriage }\end{array}$ & $\begin{array}{c}\text { 10 years after } \\
\text { marriage }\end{array}$ & $\begin{array}{c}\text { 20 years after } \\
\text { marriage }\end{array}$ \\
\hline Number of children & 0.9 & 1.4 & 1.9 & 2.4 \\
Children aged 0 & 0.2 & 0.1 & 0.1 & 0.0 \\
Children aged 1 to 5 & 0.6 & 1.2 & 0.6 & 0.1 \\
Children aged 6 to 12 & 0.0 & 0.0 & 1.2 & 0.5 \\
Children aged 13 and & 0.0 & 0.0 & 0.0 & 1.8 \\
above & & & 75.0 & 83.1 \\
Have boy(s) & 43.0 & 61.2 & 13,416 & 9,815 \\
Sample size & 15,874 & 14,874 & & \\
\hline
\end{tabular}

Note: the units of measurement in the table are all "persons" except for "Have boy(s)," which are percentages. 
Table 3 Distribution of marital status in 2010

\begin{tabular}{lcc}
\hline Marital status & Quantity (couples) & Percentage (\%) \\
\hline Presently married & 14,315 & 86.9 \\
Divorced & 591 & 3.6 \\
Widowed & 1,560 & 9.5 \\
Total & 16,466 & 100 \\
\hline
\end{tabular}

baseline hazard function of divorce. Since $\alpha(t)$ is the same for all first marriages, the differences between $\log h_{j}(t)$ no longer contain $\alpha(t)$; this is why the Cox proportional hazards model does not require assumptions regarding the function form of the divorce hazard function. The two terms on the right side of the equation except $\alpha(t)$ portray the divorce risks among different kinds of couples. The term $x_{i}$ represents a group of time-constant independent variables, such as wife's years of education and age at first marriage. $\beta$ is the regression coefficient of $x_{i} ; x_{i}(t)$ represents a set of time-varying independent variables, such as the number of children, children's age, and gender. The term $\gamma$ is the regression coefficient of $x_{i}(t)$.

To include time-varying variables in the analysis, this study converts the data into person-year format. When the model is set, all first marriages are under risk of divorce from the beginning of the marriage. Couples who were still married in 2010 are constantly in the risk set. Divorced and widowed couples exit the risk set after the occurrence of the event. The variable that indicates the occurrence of divorce is assigned the value of 1 for divorced couples only in the year when the divorce occurred; the value assigned to married and widowed couples during the risk set is always 0 .

\section{Results}

\section{Bivariate descriptive analysis}

Figure 4 shows the Kaplan-Meier survival function for couples with and without premarital births, which shows that couples with premarital birth have a much higher divorce risk than those with no premarital births.

Figure 5 describes the Kaplan-Meier survival function of divorce by number of children. As is seen in the graph, the height of the four survival curves is arranged in strict order of the number of children. The survival curve corresponding to childless couples lies in the lowest position, and the survival curve for couples with three or more children lies in the highest position. This shows that the greater the number of children, the smaller the possibility of divorce.

Further investigation reveals that the gap between couples with no children and with one child is wide, the gap between couples with one child and two children is relatively narrower, and the gap between couples with two and three or more children is the narrowest. Therefore, intuitively, the marginal effect of the number of children on marital stability diminishes with the increase in the number.

Figure 6 depicts the divorce risk between those who have boys and those who do not among couples who have at least one child. As is seen, the survival curve for couples with boy(s) is significantly higher than those who do not have boy(s); that is, couples with sons have higher marital stability. 


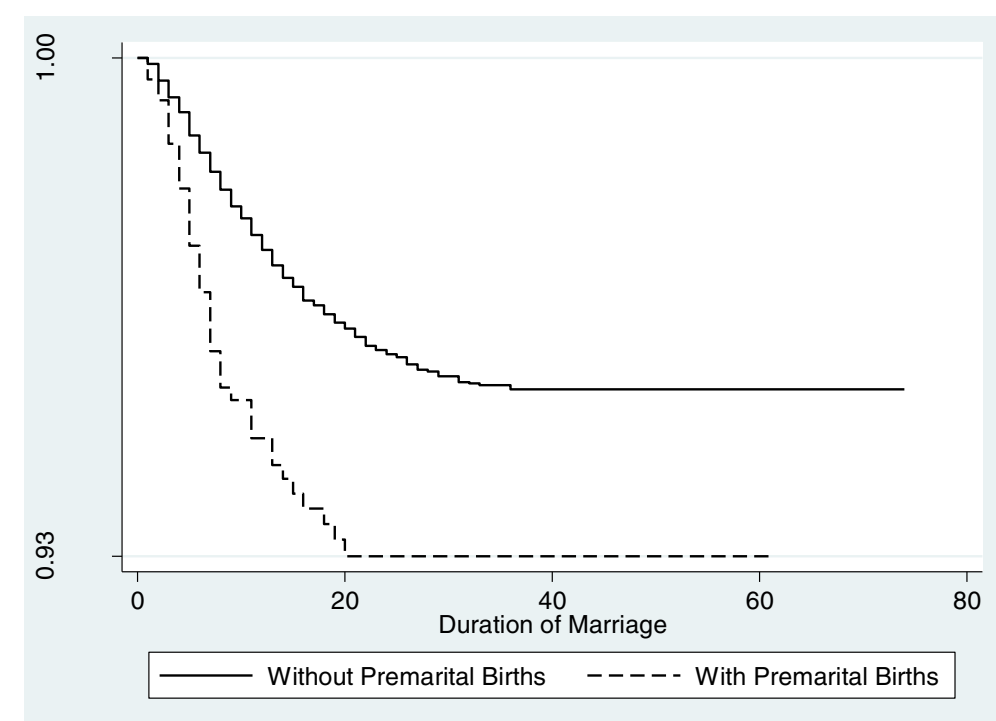

Figure 4 Kaplan-Meier survival estimates for couples with and without premarital births.

As can be seen in Figures 4, 5, 6, survival curves are parallel and there are no intersects, indicating that the independent variables involved in the figures meet the proportional hazard assumptions underlying the Cox proportional hazards model. In addition to these variables, we also tested the proportional hazard for each of the control variables one by one, using the graphic method prior to applying the Cox model. This showed that all variables meet this assumption.

Take historical periods as an example. As is shown in Figure 7, the survival curves are roughly parallel to each other and have no intersections. Consistent with the literature review, the divorce rate is the lowest in the period 1966 to 1980, which is associated with a particular political environment. After this particular historical period, the

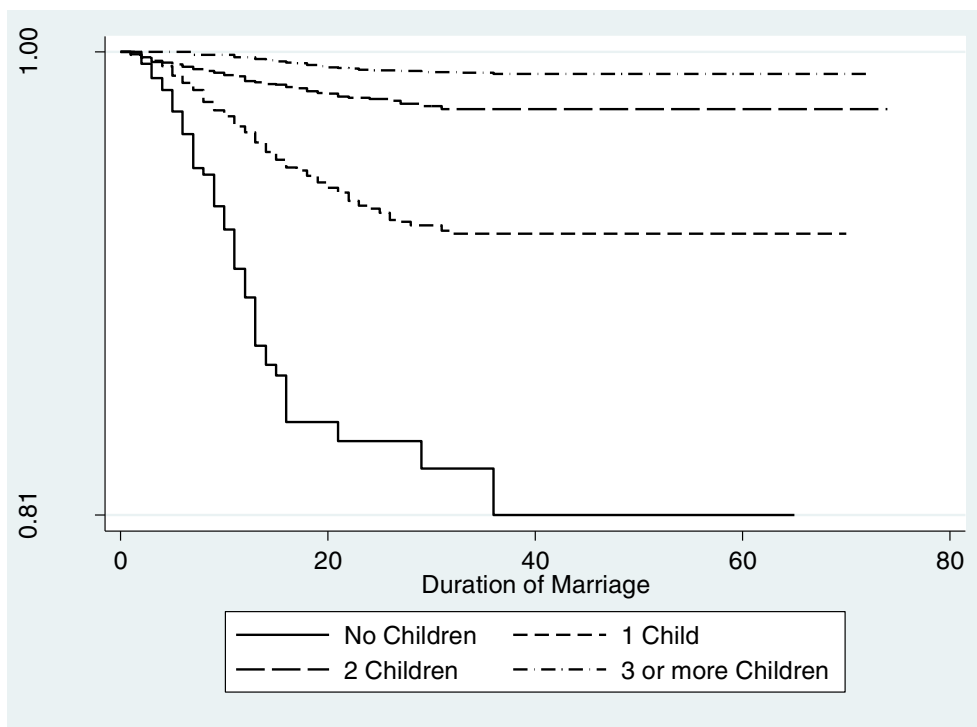

Figure 5 Kaplan-Meier survival estimates by number of children. 


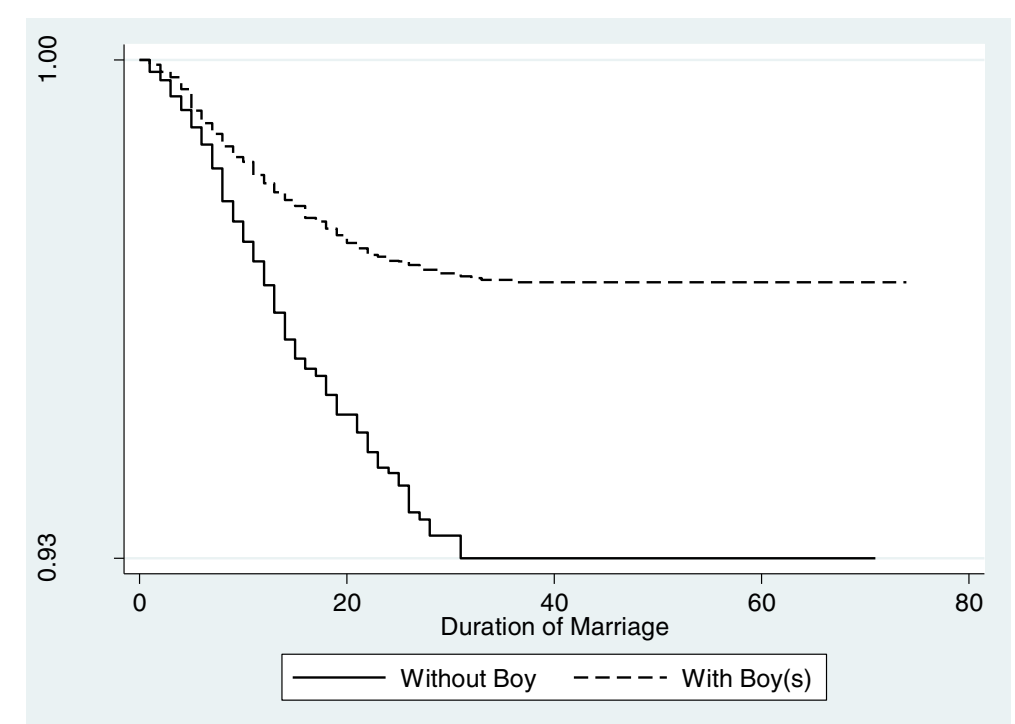

Figure 6 Kaplan-Meier survival estimates for couples with and without boy(s).

divorce rate rises continuously with time, which is also consistent with the previous findings.

In this paper, we used the Cox proportional hazards model. To test the robustness of the results, we also tried other modeling methods. Figure 7 shows that the survival function for each historical periods does not display any intersection; however, considering that the survival function in different periods may have different shapes, we also applied a stratified Cox model. We treated different historical periods as different layers and found that this was entirely consistent with the results obtained by the Cox model. In addition, when one takes into account that the measurement for the time of divorce is in years, this may not satisfy the assumption of a continuous-time risk model of the

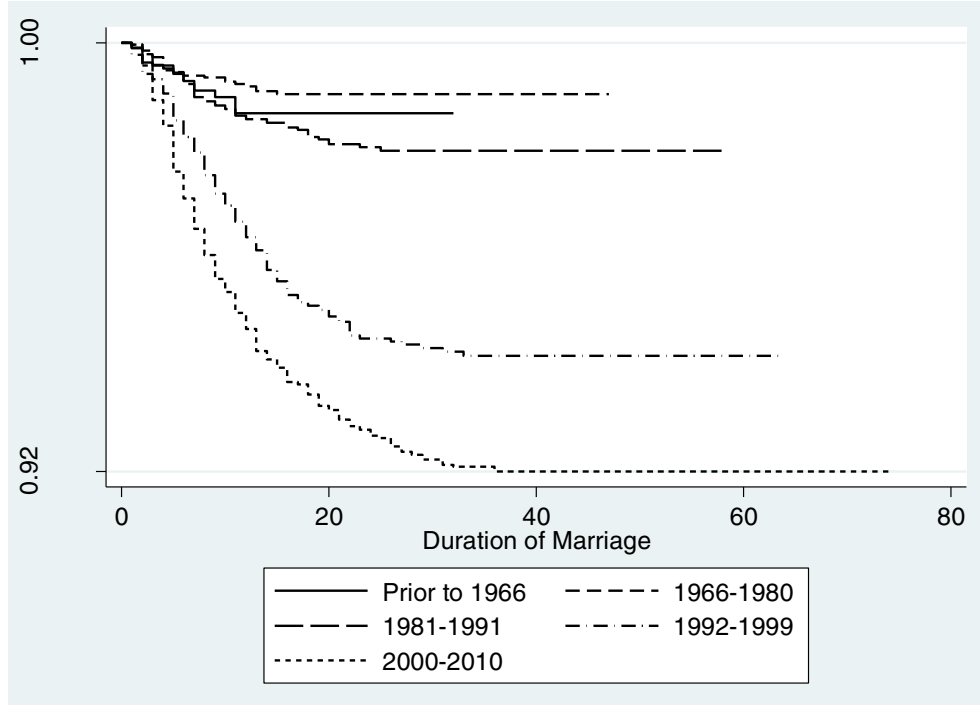

Figure 7 Kaplan-Meier survival estimates by historical periods. 
Cox model. We also tried a discrete-time hazard model and found that the results from this model were consistent with the Cox model. Due to space limitations, we only report the estimation results of the Cox model.

\section{Results of model analysis}

Table 4 shows the results of the Cox proportional hazards model. In addition to controlling for the duration of marriage, all models controlled for historical periods, provinces, urban/rural areas, wife's age at first marriage, and wife's years of completed education. Because of space limitations, the regression coefficients for each province are not reported in the table.

According to the regression coefficients of the four historical periods, the divorce risk during 1966 to 1980 was lower than before 1966, and the divorce risk during 1981 to 1991 was higher than before 1966. However, both the statistical tests are not significant. In contrast, the divorce risk of the two historical periods after 1992 is significantly higher, with the highest after 2000.

Divorce risk is higher for urban couples than rural couples. The younger the wife's age at first marriage and the higher her level of education, the higher the divorce risk. This is consistent with previous findings. In Models 5 and 6, the statistical tests for the coefficient of urban/rural areas are not significant after adding the interaction term. With interactions in the model, the theoretical meaning of the main effect of urban/ rural areas differs from the previous four models, so they cannot be directly compared.

Model 1 included whether couples had a premarital birth and the number of children. Even after controlling for other variables, the divorce risk for couples with premarital birth is still higher and statistically significant. From Model 1 to Model 6, the regression coefficients and the results of statistical tests are very consistent, which fully demonstrates that premarital birth is not favorable to the stability of marriage. Therefore, Hypothesis 1 is supported by the model.

Model 1 also shows that after controlling for other variables, the divorce risk significantly decreases as the number of children increases. But different from Model 1 that assumes a linear relationship between number of children and divorce risk, Model 2 assumed a U-shaped quadratic relationship. The statistical test for the quadratic term of the number of children is very significant, suggesting the existence of a nonlinear relationship between the number of children and divorce risk.

Based on simple calculation, when the number of children is equal to 4.3, the quadratic curve drops down to the lowest point. Since the majority of the couples in the sample have fewer than five children, it can generally be assumed that the divorce risk decreases as the number of children increases, but due to the presence of the quadratic term, the rate of decline is not linear. The decline is largest when the number of children increases from 0 to 1 and is smaller when the number increases from 1 to 2 , and so on. Further analysis found that if the number of children is included in the model as a categorical variable, couples with four children and couples with five or more children have roughly the same divorce risk (results are not presented in the table). That is, when the number of children increases to four, further increase does not reduce the divorce risk. This finding fully demonstrates that the number of children has diminishing marginal effects on marriage stability, which confirms Hypothesis 2. 
Table 4 Results of the Cox proportional hazards model

Period (before $1966=0$ )

1966 to 1980

1981 to 1991

1992 to 1999

2000 to 2010

Urban (rural =0)

Wife's age at first marriage

Wife's years of education

Premarital birth $(\mathrm{no}=0)$

No. of children

Square of no. of children

No. of children aged 0

No. of children aged 1 to 5

No. of children aged 6 to 12

No. of children aged 13

and above

Have boy $(\mathrm{no}=0)$

Urban $\times$ no. of children aged 0

Urban $\times$ no. of children aged 1 to 5

Urban $\times$ no. of children aged 6 to 12

Urban $\times$ no. of children aged 13 and above

Urban $\times$ have boy
Model 1

$0.406(0.280)$

$1.287^{* * *}(0.269)$

$1.430 * * *(0.270)$

$0.461^{* * *}(0.102)$

$-0.048^{* * *}(0.013)$

$0.054^{* * *}(0.011)$

$1.589^{* * *}(0.171)$

$-1.051^{* * *}(0.076)$

Model 2
$-0.036(0.311)$
$0.491(0.280)$
$1.401^{* * *}(0.269)$
$1.553^{* * *}(0.270)$
$0.466^{* * *}(0.103)$
$-0.047^{* * *}(0.013)$
$0.055^{* * *}(0.011)$
$1.591^{* * *}(0.172)$
$-1.554^{* * *}(0.103)$
$0.180^{* * *}(0.021)$

Model 3

$-0.021(0.311)$

$0.406(0.281)$

$1.276^{* * *}(0.270)$

$1.422^{* * *}(0.270)$

$0.469^{* * *}(0.102)$

$-0.050^{* * *}(0.013)$

$0.054^{* * *}(0.011)$

$1.446^{* * *}(0.179)$

$-2.070^{* * *}(0.311)$

$-1.083^{* * *}(0.105)$

$-0.979^{* * *}(0.111)$

$-0.783^{* * *}(0.128)$

$-0.969^{* * *}(0.108)$

$-0.879^{* * *}(0.113)$

$-0.701^{* * *}(0.128)$

$-0.327^{* * *}(0.096)$

$-0.32$

$$
-0 .
$$$$
0.421 *(0.185)
$$$$
0.612^{* * *}(0.169)
$$$$
0.553^{* * *}(0.152)
$$

$0.590^{* * *}(0.170)$ 
Table 4 Results of the Cox proportional hazards model (Continued)

\begin{tabular}{|c|c|c|c|c|c|c|}
\hline LR chi-square & $775.8^{* * *}$ & $804.0^{* * *}$ & $795.0^{* * *}$ & $806.7^{* * *}$ & $827.8^{* * *}$ & $818.9^{* * *}$ \\
\hline$d f$ & 33 & 34 & 36 & 37 & 41 & 38 \\
\hline N & 16,466 & 16,466 & 16,466 & 16,466 & 16,466 & 16,466 \\
\hline
\end{tabular}

Note: (1) these models also controlled for provinces, but due to space limitations, the coefficients for each province are not reported in the table. (2) * $p<0.05,{ }^{* *} p<0.01,{ }^{* * *} p<0.001$. 
Model 3 divided children into four age groups. In the different age groups, an increase in the number of children has a protective effect on marriage. The impact is the largest for children aged 0 , then those aged 1 to 5 , followed by those aged 6 to 12; children aged 13 years old and over have the minimum impact.

To test the effects of children's age, we imposed a linear constraint on the four age groups, that is, they were treated as having the same effect. Results of likelihood ratio chi-square showed that the fit of the model was significantly lowered $(p<0.01)$ after the constraint. This demonstrates that the regression coefficients of the four variables are not equal, that is, children of different ages have different effects on divorce risk. From the coefficients, we can conclude that the younger the children, the greater the protective effect. Therefore, Hypothesis 3 is supported as well.

Model 4 added a variable indicating whether a couple has a boy on the basis of Model 3. As is shown in the table, after controlling for other variables, the divorce risk is significantly lower for couples with boys. Therefore, Hypothesis 4 is also supported.

In Model 5, we added the interaction terms of urban/rural areas with the number of children based on Model 4. The effects of the number of children aged 0 have no significant differences between urban and rural areas, but the effects for those aged 1 to 5 , those aged 3 to 12, and children aged 13 and older are all significantly different. The regression coefficients of the three interaction terms are positive, which indicates that the protective effect on marriage of children in urban areas is weaker than in rural areas. Therefore, Hypothesis 5 is supported.

Finally, Model 6 incorporated the interaction term of urban/rural areas and the gender of children based on Model 4. The estimate of the interaction is significantly positive, which indicates that the effect of boys is weaker in urban areas than in rural areas. Therefore, Hypothesis 6 is also supported.

\section{Discussion and conclusions}

Existing studies show that premarital births and the number, age, and gender of children have significant impacts on couples' divorce risk, but no study has systematically examined the relationships between children and divorce risk in China to date. Based on the first wave of the CFPS in 2010, this study explores this issue for the first time.

We found that all the above variables have significant impacts on divorce risk in China. Specifically, couples with no premarital births have lower divorce risk, and the greater the number of children, the more stable is the marriage. However, the protective effects of the number of children have diminishing marginal effects; the lower the child's age, the lower is the divorce risk, and couples with boys have lower divorce risk. These findings are all consistent with the results of previous studies in Western societies, which demonstrates that, as a link between the couple, children are extremely important for maintaining a stable marital relationship and resolving family conflicts.

In addition, this study found that the impact of children on divorce risk is significantly different between urban and rural areas. The protective effect of children is stronger in rural areas than in urban areas, and the protective effect of boys is stronger in rural areas as well. These differences may reflect the huge gap in terms of the level of socioeconomic development and cultural traditions between urban and rural areas. 
Due to special cultural traditions, China's divorce rates have long been low. In traditional Chinese culture, the intent of marriage was not the love and happiness of the couple, but for childbearing and rearing, the whole family. Therefore, it is essentially different from that in Western society (Zeng 1995). However, since the introduction of the reform and the opening-up policy, China has undergone substantial changes in terms of economic growth and cultural values. With the rapid pace of socioeconomic and cultural changes, people's concept of marriage and the family has also changed dramatically and drastically (Zeng 1995).

This study found that, compared with the relatively isolated rural areas, the effect of children on marriage stability is significantly weaker than in the relatively more developed urban areas. To some degree, this confirms the impact of the change in the concept of marriage and public opinions on divorce. In addition, premarital birth is not favorable to the stability of marriage, which also confirms that an open attitude toward marriage leads to higher divorce risks. All these findings show that change in the marriage concept is an important reason for the recent increase in China's divorce rate. It is foreseeable that with the rapid pace of economic increase and cultural change, China's divorce rates will continue to rise.

In addition to the changes in the concept of marriage, the impact of the declining fertility rate on the stability of marriage should not be neglected. Due to the implementation of a strict family planning policy and overall socioeconomic development, China's fertility rates have continued to decrease since the 1970s (see Figure 2). The decline in the fertility rate lowered the rate of population growth, which made tremendous contributions to China's socioeconomic development. On the other hand, for families, the decline in the fertility rate means the decline of couples' joint resources or the decline of specific marriage capital. At the same time, it also means that the chance of having a boy is reduced, and the duration of having a young child in the family is shortened, thereby greatly increasing the instability of marriage and the family.

Although this study does not directly discuss the relationship between the fertility rate and divorce rate, the findings imply an association between the two. Therefore, one can assume that the decline in the fertility rate may be an important cause for the increase in the divorce rate.

\section{Endnotes}

${ }^{a}$ The population replacement level is the fertility rate required to maintain the population. It varies with the mortality rate. For the current mortality rate in China, scholars usually use the replacement level of 2.1 (Guo 2004).

${ }^{b}$ Unreasonable values refer to date of divorce or being widowed occurring earlier than the start of the first marriage. The numbers of the two kinds of unreasonable values are six and three, respectively; thus, deleting them does not significantly affect the entire sample.

${ }^{c}$ At the beginning of the first marriage, the historical period is the same as the date of marriage. As time goes on, historical periods change. For example, a couple that married in 1966 and were still married in 2010 when the survey was conducted would have experienced five different historical periods. In the analysis, the time-varying variable representing the period can capture this change. 


\section{Competing interests}

The authors declare that they have no competing interests.

\section{Authors' contributions}

QX carried out the study and drafted the manuscript. JY and ZQ both did much auxiliary work and provided many constructive suggestions to the study. All authors read and approved the final manuscript.

\section{Author details}

${ }^{1}$ School of Social and Behavioral Sciences, Nanjing University, 163 Xianlin Avenue, Qixia District, 210023 Nanjing, Jiangsu Province, China. ${ }^{2}$ Shanghai Development Research Institute, Shanghai Party Institute of CCP, No. 200 South HongCao Road, 200233 Shanghai, China. ${ }^{3}$ Department of Sociology, Peking University, 5 Yiheyuan Road, 100871 Beijing, China.

\section{Received: 16 December 2014 Accepted: 3 March 2015}

Published online: 17 April 2015

\section{References}

Allison, Paul D. 1995. Survival analysis using the SAS system: a practical guide. Cary, NC: SAS Publishing. Andersson, G. 1997. The impact of children on divorce risks of Swedish women. European Journal of Population 13(2):109-145.

Andersson, Gunnar, and Gebremariam Woldemicael. 2001. Sex composition of children as a determinant of marriage disruption and marriage formation: evidence from Swedish Register Data. Journal of Population Research 18, no. 2:143-153.

Becker, Gary S. 1973. A theory of the allocation of time. Economic Journal 81: 813-847.

Becker, Gary S, Elizabeth Landes, and Robert T Michael. 1977. An economic analysis of marital instability. Journal of Political Economy 85(6):1141-1187.

Belsky, J, GB Spanier, and M Ravine. 1983. Stability and change in marriage across the transition to parenthood. Journal of Marriage and the Family 45: 567-577.

Bracher, M, G Santow, SR Morgan, and J Trussell. 1993. Marriage dissolution in Australia: models and explanations. Population Studies 47:403-425.

Cherlin, Andrew. 1977. The effect of children on marital dissolution. Demography 14: 265-272.

Coppola, L, and M Di Cesare. 2008. How fertility and union stability interact in shaping new family patterns in Italy and Spain. Demographic Research 18(4):117-144.

Diekmann, Anddreas, and Kurt Schmidheiny. 2004. Do parents of girls have a higher risk of divorce? An eighteencountry study. Journal of Marriage and Family 66:651-660.

Durkheim, Emile. 2000. De La Division Du Travail Social. Trans. DongQu. Shanghai: SDX Joint Publishing.

Fei, Xiaotong. 1999. The institutions for reproduction. Beijing: Shangwu Press.

Freedman, Deborah, and Arland Thornton. 1979. The long-term impact of pregnancy at marriage on the family's economic circumstances. Family Planning Perspectives 11(1):6-21.

Furstenberg Jr, FF, Christine Winquist Nord, James L Peterson, and Zill Nicholas. 1983. The life course of children of divorce: marital disruption and parental contact. American Sociological Review 48(5):656-667.

Glenn, ND, and Sara Mclanahan. 1982. Children and marital happiness: a further specification of the relationship. Journal of Marriage and Family 44: 63-72.

Goode, WJ. 1993. World changes in divorce patterns. New Haven/London: Yale University Press.

Guo, Zhigang. 2004. Studies and discussion on China's fertility level in the 1990s. Population Research No. 2: 10-19. Heaton, Tim B. 1990. Marital stability throughout the child-rearing years. Demography 27, no. 1:55-63.

Hoem, B, and JM Hoem. 1992. Disruption of marital and non-marital unions in Sweden. In Demographic applications of event history analysis, ed. J Trussell, R Hankinson, and J Tilton, 61-84. Oxford: Clarendon Press.

Hoffman, LW, and JD Manis. 1978. Influences of children on marital interaction and parental satisfactions and dissatisfactions. In Child influences on marital and family interaction: a life-span perspective, ed. R Lehnerand and GB Spanier, 165-213. New York: Academic Press.

Institute of Population and Labor Economics, The Chinese Academy of Social Sciences. 2010. Almanac of China's Population 2010. Beijing: Economic and Management Press.

Jalovaara, M. 2001. Socio-economic status and divorce in first marriages in Finland: 1991-1993. Population Studies 55(2):119-133.

Katzev, Aphra R, Rebecca L Warner, and Alan C Acock. 1994. Girls or boys? Relationship of child gender to marital instability. Journal of Marriage and Family 56(1):89-100.

Lyngstad, Torkild Hovde. 2004. The impact of parents' and spouses' education on divorce rates in Norway. Demographic Research 10:119-142.

McLanahan, Sara, and Larry Bumpass. 1988. Intergenerational consequences of family disruption. American Journal of Sociology 94(1):130-152.

Morgan, SPhilip, Diane N Lye, and Gretchen A Condran. 1988. Sons, daughters, and the risk of marital disruption. American Journal of Sociology 94(1):110-129.

Rollins, BC, and R Galligan. 1978. The developing child and marital satisfaction of parents. In Child influences on marital and family interaction: a life-span perspective, ed. R Lehner and GB Spanier, 71-105. New York: Academic Press.

Teachman, Jay D, and Alex Heckert. 1985. The impact of age and children on remarriage. Journal of Family Issues 6(2):185-203.

Thornton, Arland. 1977. Children and marital stability. Journal of Marriage and Family 39(3):531-540.

Tzeng, J, and RD Mare. 1995. Labour market and socio-economic effect on marital stability. Social Science Research 24:329-351.

Udry, JRichard. 1971. The social context of marriage, 2nd ed. Philadelphia: J. B. Lippincott Company. 
Vignoli, Daniele, and Irene Ferro. 2009. Rising marital disruption in Italy and its correlates. Demographic Research 20:11-36.

Waite, Linda J, and Lee A Lillard. 1991. Children and marital disruption. American Journal of Sociology 96(4):930-953. Weiss, Y, and RJ Willis. 1997. Match quality, new information and marital dissolution. Journal of Labor Economics 15:S293-S329.

White, LK. 1990. Determinants of divorce: a review of research in the eighties. Journal of Marriage and Family 52:904-912.

Worthington, EJ, and BG Buston. 1986. The marriage relationship during transition to parenthood: a review and a model. Journal of Family Issues 7:443-473.

Wu, Deqing. 1999. Status quo and trend of divorce in contemporary China. Beijing: Cultural Relics Press.

Xie, Yu. 2006. Sociological methodology and quantitative research. Beijing: Social Sciences Academic Press.

Ye, Wenzhen, and Qingguo Lin. 1998. Analysis of trend and cause of divorce in contemporary China. Population and Economics No. 3:22-28.

Zeng, Yi. 1995. Studies of divorce in China in the 1980s. Beijing: Peking University Press.

Submit your manuscript to a SpringerOpen ${ }^{0}$ journal and benefit from:

- Convenient online submission

- Rigorous peer review

- Immediate publication on acceptance

- Open access: articles freely available online

- High visibility within the field

- Retaining the copyright to your article

Submit your next manuscript at $>$ springeropen.com 